\title{
Combined acupuncture and general anesthesia on immune and cognitive function in elderly patients following subtotal gastrectomy for gastric cancer
}

\author{
NINGKE WANG, YANGWEN OU and WENXIANG QING \\ Department of Anesthesiology, The Third Xiangya Hospital of Central South University, Changsha, Hunan 410013, P.R. China
}

Received June 23, 2017; Accepted September 25, 2017

DOI: $10.3892 / \mathrm{ol} .2017 .7262$

\begin{abstract}
This study investigated the effects of acupuncture combined with general anesthesia on postoperative immune and cognitive functions in elderly patients undergoing subtotal gastrectomy. We recruited 96 elderly patients who received anesthesia for subtotal gastrectomy and randomly divided them into control $(n=48)$ and experimental $(n=48)$ groups. The control group received general anesthesia and the experimental group received combined acupuncture and general anesthesia. We measured hemodynamic immediately before and after anesthesia induction, and immune observations before and after surgery. We found no significant differences in mean heart rate (HR), mean oxygen saturation $(\mathrm{SpO} 2)$, and partial pressure of end-tidal carbon dioxide (PETCO2) in the perioperative period between the two groups. Mean arterial pressure (MAP) was lower in the experimental group than that in the control group $(\mathrm{P}<0.05)$. The levels of cluster of differentiation $3\left(\mathrm{CD}^{+}\right), \mathrm{CD}^{+}$and $\mathrm{CD} 4^{+} / \mathrm{CD}^{+}$in both groups were significantly lower after surgery in both groups $(\mathrm{P}<0.05)$. We also found some time-points in which the immune markers where significantly higher in the experimental group. In terms of adverse reactions, there were no differences in nausea, vomiting, and hypoxemia between the two groups $(\mathrm{P}>0.05)$, but the incidence of delayed recovery and postoperative agitation were significantly lower in the experimental group compared with those in the control group $(\mathrm{P}<0.05)$. One day after surgery, the experimental group showed better protection of cognitive function than the control group $(\mathrm{P}<0.05)$. Overall, combined acupuncture and general anesthesia in elderly gastric cancer patients receiving subtotal gastrectomy showed more stable hemodynamics and fewer stress responses during
\end{abstract}

Correspondence to: Professor Yangwen Ou, Department of Anesthesiology, The Third Xiangya Hospital of Central South University, 138 Tongzipo Road, Yuelu, Changsha, Hunan 410013, P.R. China

E-mail: yok4ii@163.com

Key words: combined acupuncture and drug general anesthesia, elderly patients, subtotal gastrectomy, immune functions, cognitive functions surgery. Thus, combined acupuncture and general anesthesia can shorten the recovery time from anesthesia, have less negative effects on immune function and decrease the incidence of postoperative cognitive impairment.

\section{Introduction}

The continuous ageing of the population and the change in eating habits, the number of elderly patients with gastric cancer has risen together with the overall increase in disease incidence. At present, the incidence and death rate of gastric cancer are second among tumors (1). Affected by imbalanced access to medical care and low awareness of the presentation of gastric cancer among other factors, gastric cancer is typically diagnosed in advanced stages. In medium and advanced stages, most tumors infiltrate into the submucosa and muscularis, or reached the serosa across the muscularis $(2,3)$. Therefore, the only option at this time is subtotal gastrectomy. With the rapid development of laparoscopic techniques, laparoscopy-assisted proximal subtotal gastrectomy has been widely applied in clinical practice, which enables thorough lymph node dissection (4). Immune dysfunction easily occurs because of surgery trauma, stress due to anesthesia, and compromised autoimmunity in elderly gastric cancer patients (5). Post-operative cognitive dysfunction (POCD) is one of the most distressing surgical problems (6). Acupuncture analgesia has a long history in China, and the combined acupuncture/general anesthesia has a good regulatory effect that is hard to be substituted by drugs. Here, we analyzed the immune and cognitive functions after general anesthesia in elderly patients undergoing subtotal gastrectomy, providing the basis for fast recovery and the prevention of POCD post-surgery.

\section{Materials and methods}

General subject information. We recruited 96 elderly patients that received general anesthesia for subtotal gastrectomy from January to December, 2016. Inclusion criteria: i) diagnosed with gastric cancer via electronic gastroscope biopsy, contrast-enhanced computed tomography (CT), or magnetic resonance imaging (MRI); ii) received surgical treatments and had complete medical records; iii) signed informed consent. Exclusion criteria: i) tumors with a maximum diameter $>10 \mathrm{~cm}$; 
Table I. General information sheet of research subjects.

\begin{tabular}{|c|c|c|c|c|}
\hline Item & Control group $(n=48)$ & Experimental group $(n=48)$ & $t / \chi^{2}$ & P-value \\
\hline Sex (male/female) & $30 / 18$ & $28 / 20$ & 0.044 & 0.835 \\
\hline Age (years) & $60-80$ & $60-85$ & & \\
\hline Average age (years) & $68.36 \pm 5.43$ & $68.74 \pm 5.57$ & 0.338 & 0.736 \\
\hline \multicolumn{5}{|c|}{ Adenocarcinoma differentiation (n, \%) } \\
\hline Well-differentiated & $23(47.92)$ & $21(43.75)$ & 0.171 & 0.918 \\
\hline Moderately differentiated & $15(31.25)$ & $16(33.33)$ & & \\
\hline Poorly differentiated & $10(20.83)$ & $11(22.92)$ & & \\
\hline \multicolumn{5}{|l|}{ Tumor size (n, \%) } \\
\hline$<3 \mathrm{~cm}$ & $14(29.17)$ & $12(25.0)$ & 0.222 & 0.895 \\
\hline $3-5 \mathrm{~cm}$ & $24(50.0)$ & $25(52.08)$ & & \\
\hline$>5 \mathrm{~cm}$ & $10(20.83)$ & $11(22.92)$ & & \\
\hline
\end{tabular}

ii) distant metastases; iii) other malignant tumors. Patients were randomly divided into experimental $(n=48)$ and control $(n=48)$ groups by a random number table. The differences in patient data between the two groups were not statistically significant $(\mathrm{P}>0.05)$ (Table I).

Anesthesia. Patients fasted for $6 \mathrm{~h}$ before surgery. $0.1 \mathrm{~g}$ phenobarbital sodium (Tianjin Kingyork Group, approval no. NMPN H12020381) and $0.5 \mathrm{mg}$ atropine (Jiangsu Lianshui Pharmaceutical, approval no. NMPN H32020166) were injected intramuscularly $30 \mathrm{~min}$ before the anesthesia, and arterial blood gas and blood pressure were monitored.

Only general anesthesia was used in the control group. After mask oxygen inhalation, midazolam (Yichang Humanwell Pharmaceutical, approval no. NMPN H20067040) at a dose of $0.05 \mathrm{mg} / \mathrm{kg}$, fentanyl (Yichang Humanwell Pharmaceutical, approval no. NMPN H42022076) at a dose of $4 \mu \mathrm{g} / \mathrm{kg}$, vecuronium bromide (Jiangsu Nhwa Pharmaceutical, approval no. NMPN H20113296) at a dose of $0.12 \mathrm{mg} / \mathrm{kg}$, and propofol (Xi'an Libang Pharmaceutical, approval no. NMPN H20010368) at a dose of $2.5 \mathrm{mg} / \mathrm{kg}$ were injected intravenously. Trachea intubation was executed after the muscles were relaxed, and then it was connected to an all-round anesthetic machine (Drager, Lübeck, Germany) for intermittent positive pressure ventilation: tidal volume, $8-10 \mathrm{~m} / \mathrm{kg}$; respiratory rate, 12 breaths/min: partial pressure of end-tidal carbon dioxide (PETCO2), 30-40 mmHg. Intermittent bolus injection of $2 \mu \mathrm{g} / \mathrm{kg} / \mathrm{h}$ fentanyl and $4 \mathrm{mg} / \mathrm{kg} / \mathrm{h}$ propofol were performed and $0.1 \mathrm{mg} / \mathrm{kg} / \mathrm{h}$ vecuronium bromide was pumped into vein to maintain the anesthesia.

Combined acupuncture and general anesthesia was used in the experimental group. Acupoints Zusanli (ST 36), Neiguan (PC 6), Hegu (LI 4), and Shangjuxu (ST 37) were positioned on both sides, and acupunctured after routine disinfection. After needling sensation was achieved, the filiform needles were connected with the electronesthesia apparatus at 80-90 times/min frequency. Then, the intensity was gradually increased to the level that was bearable to the patients and the stimulation time was 15-20 min. After that, the same methods applied in the control group were used for induction of general anesthesia.
Surgery. The patients were in supine position with legs wide apart. An observation hole was set around the umbilicus in which a cavity mirror was placed. Three to four surgical holes were selected to place the laparoscope. Lymph nodes in the pyloric region, upper region of pancreas, lesser curvature of stomach, hilus of spleen, and left cardiac region were dissected in sequence. A median incision was made lengthwise under the xiphoid and then the body of the stomach was taken out of the abdominal cavity after a protector was put in the incision. The proximal portion of the stomach was resected and a no. 24 stapler was implanted for stoma of remnant stomach under the laparoscope; the abdominal cavity was washed to place the drainage tube after the anterior wall of the stomach was sutured.

Immune indexes. Venous blood $(5 \mathrm{ml})$ of the patients were collected $30 \mathrm{~min}$ before anesthesia $(\mathrm{C} 0)$, during surgery $(\mathrm{C} 1)$, immediately after surgery (C2), $24 \mathrm{~h}$ after surgery (C3), and $72 \mathrm{~h}$ after surgery (C4). Then, the venous blood was separated by centrifugation and serum was extracted. Anti-human cluster of differentiation 3 (CD3), CD4, and CD8 antibodies were added separately into the serum and incubated in the dark at $4^{\circ} \mathrm{C}$ for $30 \mathrm{~min}$. The percentages of $\mathrm{CD}^{+}, \mathrm{CD}^{+}$and $\mathrm{CD}^{+}$were measured using flow cytometry (Partec, Münster, Germany).

Evaluation methods. For hemodynamics, we measured heart rate (HR), mean arterial pressure (MAP), oxygen saturation (SpO2), and PETCO2 immediately before anesthesia induction (T1), 1 min after intubation (T2), 5 min into the surgery (T3), and $10 \mathrm{~min}$ into the surgery (T4).

Venous blood was collected at $\mathrm{C} 0, \mathrm{C} 1, \mathrm{C} 2, \mathrm{C} 3$ and $\mathrm{C} 4$, and the levels of T-lymphocyte subsets $\left(\mathrm{CD}^{+}, \mathrm{CD}^{+}, \mathrm{CD}^{+}\right.$and $\left.\mathrm{CD} 4^{+} / \mathrm{CD}^{+}\right)$were measured using flow cytometry. Adverse reactions, including nausea and vomiting, hypoxemia, delayed recovery, and postoperative agitation, we recorded.

The Montreal Cognitive Assessment (MoCA) scale (7) and Mini-Mental State Examination (MMSE) (8) were used to evaluate the cognitive function one day before and one day after surgery. The MoCA scale was evaluated in 8 aspects: space and executive capability, memory, attention, naming, language, 
Table II. Hemodynamic indexes in different periods.

\begin{tabular}{|c|c|c|c|c|c|c|}
\hline Index & Group & Cases & $\mathrm{T} 1$ & $\mathrm{~T} 2$ & $\mathrm{~T} 3$ & $\mathrm{~T} 4$ \\
\hline \multirow[t]{2}{*}{ HR (bpm) } & Experimental & 48 & $85.13 \pm 6.35$ & $74.73 \pm 6.42^{\mathrm{a}}$ & $68.24 \pm 5.35^{\mathrm{a}}$ & $64.74 \pm 5.78^{a}$ \\
\hline & Control & 48 & $84.38 \pm 6.72$ & $75.05 \pm 6.13^{\mathrm{a}}$ & $67.94 \pm 5.38^{\mathrm{a}}$ & $65.13 \pm 5.48^{\mathrm{a}}$ \\
\hline \multirow[t]{2}{*}{$\mathrm{SpO} 2(\mathrm{mmHg})$} & Experimental & 48 & $99.36 \pm 0.41$ & $98.74 \pm 0.35$ & $97.56 \pm 0.28$ & $99.48 \pm 0.27$ \\
\hline & Control & 48 & $99.23 \pm 0.32$ & $98.58 \pm 0.28$ & $97.42 \pm 0.37$ & $99.36 \pm 0.18$ \\
\hline \multirow[t]{2}{*}{ PETCO2 (mmHg) } & Experimental & 48 & $35.74 \pm 1.46$ & $35.44 \pm 1.36$ & $35.58 \pm 1.27$ & $35.93 \pm 1.33$ \\
\hline & Control & 48 & $35.83 \pm 1.32$ & $35.56 \pm 1.72$ & $35.74 \pm 1.35$ & $35.78 \pm 1.57$ \\
\hline
\end{tabular}

${ }^{a} \mathrm{P}<0.05$ compared with T1 within the group. HR, heart rate; PETCO2, partial pressure of end-tidal carbon dioxide; SpO2, oxygen saturation.

Table III. MAP levels in different periods $(\mathrm{mmHg})$.

\begin{tabular}{lccccc}
\hline Group & Cases & $\mathrm{T} 1$ & $\mathrm{~T} 2$ & $\mathrm{~T} 3$ & $\mathrm{~T} 4$ \\
\hline Experimental & 48 & $56.83 \pm 3.72$ & $67.38 \pm 4.26$ & $65.32 \pm 3.25$ & $57.14 \pm 3.45$ \\
Control & 48 & $58.15 \pm 3.65$ & $79.56 \pm 4.38$ & $75.63 \pm 3.47$ & $59.48 \pm 3.63$ \\
t-test & & 1.755 & 13.811 & 15.024 & 3.237 \\
P-value & & 0.083 & $<0.001$ & $<0.001$ & 0.002
\end{tabular}

MAP, mean arterial pressure.

Table IV. CD3 ${ }^{+}$levels at different times (\%).

\begin{tabular}{lccccc}
\hline Group & $\mathrm{C} 0$ & $\mathrm{C} 1$ & $\mathrm{C} 2$ & $\mathrm{C} 3$ & $\mathrm{C} 4$ \\
\hline Experimental & $54.83 \pm 3.54$ & $50.35 \pm 3.42$ & $43.57 \pm 3.45^{\mathrm{a}}$ & $44.64 \pm 3.66^{\mathrm{a}}$ & $47.54 \pm 3.63^{\mathrm{a}}$ \\
Control & $55.16 \pm 3.35$ & $51.48 \pm 3.57$ & $45.46 \pm 3.37^{\mathrm{a}}$ & $49.57 \pm 3.73^{\mathrm{a}}$ & $49.18 \pm 3.78^{\mathrm{a}}$ \\
t-test & 0.469 & 1.584 & 2.715 & 6.536 & 2.168 \\
P-value & 0.640 & 0.117 & 0.008 & $<0.001$ & 0.033 \\
\hline
\end{tabular}

${ }^{\mathrm{a}} \mathrm{P}<0.05$ compared with $\mathrm{C} 0$ within the group.

delayed recall, abstract thinking and orientation, with a total of 30 points. Score $<26$ indicated impairment of cognitive functions. MMSE was graded in 5 aspects: orientation, language, recall, attention, and calculating ability. i) Mild cognitive impairment: 21-24 points; ii) moderate cognitive impairment: 11-20 points; iii) severe cognitive impairment: 0-10 points.

Statistical analysis. SPSS 19.0 (SPSS, Chicago, IL, USA) software was used for data processing. All the measurement data were presented as mean \pm standard deviation (mean \pm SD). t-test was used for comparing intra-group data at different time-points; enumeration data were presented as rates and $\chi^{2}$ test was applied. $\mathrm{P}<0.05$ suggested that the difference was statistically significant.

\section{Results}

Hemodynamics. We first compared the hemodynamic indexes of the patients during different phases of anesthesia (Table II).
HR significantly decreased in T3 compared with T1 in both groups, but we found no significant differences between the two groups in $\mathrm{HR}, \mathrm{SpO} 2$ (no hypoxemia occurred during the operation), and PETCO2 ( $<40 \mathrm{mmHg}$ in both groups). However, MAP after anesthesia was significantly lower in the experimental group than that in the control group (Table III).

Immune indexes. The levels of $\mathrm{CD}^{+}, \mathrm{CD}^{+}$, and $\mathrm{CD}^{+} / \mathrm{CD}^{+}$ were significantly lower in both groups at $\mathrm{C} 2-\mathrm{C} 4$ compared with those at $\mathrm{C} 0$ (Tables IV, V and VII). At $\mathrm{C} 2$, the level of $\mathrm{CD}^{+}$was significantly higher in the experimental group than that in the control group (Table IV). At C3, the levels of $\mathrm{CD}^{+}$ and $\mathrm{CD} 4^{+}$were higher in the experimental group than those in the control group (Tables IV and V). At C4, the levels of $\mathrm{CD}^{+}$, $\mathrm{CD}^{+}$and $\mathrm{CD}^{+} / \mathrm{CD}^{+}$were significantly higher in the experimental group than those in the control group (Tables IV-VII).

Adverse events. The analysis of adverse reactions after operation showed no obvious differences in nausea and vomiting, 
Table V. CD4 ${ }^{+}$levels at different times (\%).

\begin{tabular}{lccccc}
\hline Group & $\mathrm{C} 0$ & $\mathrm{C} 1$ & $\mathrm{C} 2$ & $\mathrm{C} 3$ & $\mathrm{C} 4$ \\
\hline Experimental & $32.76 \pm 3.72$ & $28.76 \pm 3.14$ & $23.46 \pm 3.38^{\mathrm{a}}$ & $21.18 \pm 3.83^{\mathrm{a}}$ & $23.48 \pm 3.15^{\mathrm{a}}$ \\
Control & $33.01 \pm 3.34$ & $28.36 \pm 3.16$ & $23.62 \pm 3.45^{\mathrm{a}}$ & $25.65 \pm 3.15^{\mathrm{a}}$ & $25.25 \pm 3.42^{\mathrm{a}}$ \\
t-test & 0.346 & 0.622 & 0.230 & 6.254 & 2.637 \\
P-value & 0.730 & 0.535 & 0.819 & $<0.001$ & 0.010 \\
\hline
\end{tabular}

${ }^{\mathrm{a}} \mathrm{P}<0.05$ intra-group comparisons.

Table VI. CD8 ${ }^{+}$levels at different times (\%).

\begin{tabular}{lccccc}
\hline Group & C0 & C1 & C2 & C3 & C4 \\
\hline Experimental & $21.74 \pm 3.06$ & $20.82 \pm 3.25$ & $20.45 \pm 3.15$ & $22.86 \pm 3.13$ & $23.52 \pm 3.27$ \\
Control & $21.92 \pm 3.12$ & $21.06 \pm 3.34$ & $20.73 \pm 3.17$ & $23.23 \pm 3.28$ & $23.48 \pm 3.38$ \\
t-test & 0.285 & 0.357 & 0.434 & 0.565 & 0.059 \\
P-value & 0.776 & 0.722 & 0.665 & 0.573 & 0.953 \\
\hline
\end{tabular}

$\mathrm{P}<0.05$ compared with $\mathrm{C} 0$ within the group.

Table VII. $\mathrm{CD}^{+} / \mathrm{CD}^{+}$levels at different times (\%).

\begin{tabular}{lccccc}
\hline Group & $\mathrm{C} 0$ & $\mathrm{C} 1$ & $\mathrm{C} 2$ & $\mathrm{C} 3$ & $\mathrm{C} 4$ \\
\hline Experimental & $1.54 \pm 0.46$ & $1.21 \pm 0.34$ & $1.17 \pm 0.37^{\mathrm{a}}$ & $1.01 \pm 0.24^{\mathrm{a}}$ & $1.03 \pm 0.34^{\mathrm{a}}$ \\
Control & $1.53 \pm 0.42$ & $1.27 \pm 0.47$ & $1.19 \pm 0.35^{\mathrm{a}}$ & $1.05 \pm 0.32^{\mathrm{a}}$ & $1.29 \pm 0.38^{\mathrm{a}}$ \\
t-test & 0.111 & 0.717 & 0.408 & 0.693 & 3.533 \\
P-value & 0.912 & 0.475 & 0.684 & 0.490 \\
\hline
\end{tabular}

${ }^{\text {aP }}<0.05$ compared with $\mathrm{C} 0$ within the group.

Table VIII. Adverse reactions after operation in two groups (n, \%).

\begin{tabular}{lccccc}
\hline Group & Cases & Nausea and vomiting & Hypoxemia & Postoperative agitation & Delayed recovery \\
\hline Experimental & 48 & $3(6.25)$ & $1(2.08)$ & $0(0.00)$ & $2(4.17)$ \\
Control & 48 & $4(8.33)$ & $2(4.17)$ & $7(14.58)$ & $3(6.25)$ \\
$\chi^{2}$ test & & 0.001 & 0.002 & 5.547 & 0.001 \\
P-value & 0.999 & 0.982 & 0.019 & 0.999 \\
\hline
\end{tabular}

Table IX. MoCA and MMSE scores in two groups.

\begin{tabular}{|c|c|c|c|c|c|c|c|c|}
\hline \multirow[b]{2}{*}{ Group } & \multicolumn{4}{|c|}{ MoCA (points) } & \multicolumn{4}{|c|}{ MMSE (points) } \\
\hline & $\begin{array}{l}1 \text { day before } \\
\text { operation }\end{array}$ & $\begin{array}{l}1 \text { day after } \\
\text { operation }\end{array}$ & t-test & $\mathrm{P}$-value & $\begin{array}{l}1 \text { day before } \\
\text { operation }\end{array}$ & $\begin{array}{l}1 \text { day after } \\
\text { operation }\end{array}$ & t-test & P-value \\
\hline Experimental & $28.63 \pm 1.54$ & $26.84 \pm 1.82$ & 5.202 & $<0.001$ & $30.38 \pm 1.56$ & $26.48 \pm 1.46$ & 12.646 & $<0.001$ \\
\hline Control & $28.72 \pm 1.62$ & $25.37 \pm 1.75$ & 9.733 & $<0.001$ & $29.94 \pm 1.62$ & $23.53 \pm 1.58$ & 19.625 & $<0.001$ \\
\hline t-test & 0.279 & 4.034 & & & 1.355 & 9.500 & & \\
\hline P-value & 0.781 & 0.001 & & & 0.179 & $<0.001$ & & \\
\hline
\end{tabular}

MoCA, Montreal Cognitive Assessment; MMSE, Mini-Mental State Examination. 
hypoxemia, and delayed recovery between the two groups. However, the incidence of postoperative agitation was significantly decreased in the experimental group ( 0 cases) compared with that in the control group (7 cases) (Table VIII).

Cognitive function. The MoCA and MMSE scores after operation were lower compared with those before operation in both groups. The decline in the experimental group was less pronounced than that in the control group (Table IX).

\section{Discussion}

Water pollution, overwork, unhealthy diet (excessive salt intake, fried, smoked and pickled food, hot diets and moldy food) as well as genetic and immune factors are implicated in gastric cancer (9). In the advanced stage, the tumors can invade the mucosa and submucosa, muscularis as well as serosa (10), which is often treated with surgery. Between total gastrectomy and proximal subtotal gastrectomy, the latter has the following advantages: Adequate excision of tumors, complete dissection of lymph nodes, simple resection and anastomosis as well as retainable gastric functions. Therefore, it is generally well accepted by patients, particularly elderly patients (11).

In the perioperative period for subtotal gastrectomy, both the surgery and anesthesia can cause stress leading to increased HR, elevated blood pressure and other changes (12). We show that the two anesthesia methods studied here caused no differences in SpO2, PETCO2 and HR. However, MAP after anesthesia was lower in experimental group, suggesting that adding acupuncture reduced hypertension responses during surgery and regulate the blood pressure in the recovery period, instead of causing abnormal changes in hemodynamics.

Generally, elderly patients have weak immunity and the stress caused by surgery can further suppress immunity (13). $\mathrm{CD}^{+}{ }^{+}$represents all the $\mathrm{T}$ lymphocytes in the body. $\mathrm{CD} 4^{+}$ belongs to the inducer $\mathrm{T}$ cell subsets, which have positive regulation of immunity. $\mathrm{CD} 8^{+}$belongs to the suppressor $\mathrm{T}$ cell subsets, which can cause disorders of immune functions (14). We found that the levels of $\mathrm{CD}^{+}, \mathrm{CD}^{+}$and $\mathrm{CD} 4^{+} / \mathrm{CD}^{+}$were lower after surgery in both groups. However, we found partial evidence for stronger immunity in the experimental group: $\mathrm{C}^{+}, \mathrm{C}^{+}$and $\mathrm{CD}^{+} / \mathrm{CD}^{+}$were higher in the experimental group at some time-points. The stress responses caused by general anesthesia can increase the secretion of catechol and epinephrine, thus leading to suppression of immune functions of the T lymphocytes (13). However, combined acupuncture and general anesthesia can control the stress responses and partially protect immune function. Systematic and bidirectional regulation on multiple organs can be realized via electro-acupuncture stimulation, which can not only mobilize pain suppression but also suppress physiological disorders and reduce stress responses to inhibit the inflammatory responses and maintain stable circulation $(15,16)$.

POCD is a mild neurocognitive dysfunction that is reversible. It often occurs after major surgeries. In particular, patients can develop cognitive impairment and mental retardation in respect to social skills, memory, and orientation after anesthesia. These problems are specifically manifested as anxiety, personality change, memory loss, abnormal cognitive ability, and disorders of mental system (17). Evidence-based medicine studies have shown that general anesthesia can lead to morphologic and biological changes of neurons, thus causing apoptosis and cell loss. Elderly patients are especially vulnerable to the effects of general anesthesia and the incidence of POCD is higher among them (18). This study showed no obvious differences in nausea, vomiting, and hypoxemia between the two groups. But the incidence of postoperative agitation was decreased in the experimental group compared with that in the control group. One day after surgery the MoCA and MMSE scores were better in the experimental group than those in the control group due to the reduction in the number of synapses and a decrease in synaptic density in the brain caused by general anesthetics. Our results show that POCD is a highly prevalent complication of major surgery (18). Combined acupuncture and general anesthesia has unique features that prevents noxious stimulation by analgesia. Acupuncture anesthesia is a non-pharmacological form of anesthesia by pain modulation mechanism activated by acupoint stimulation. On achieving the same anesthetic effect, acupuncture anesthesia can considerably reduce the use of anesthetic drugs, lowering the incidence of adverse reactions. Furthermore, acupuncture combined with drugs can effectively suppress the central nervous system, improve microcirculation and oxygen metabolism of brain tissues, increase cerebral blood supply, relieve cerebral edema, and reduce inflammatory responses in the hippocampus caused by inflammatory factors crossing the blood-brain barrier (19). In addition, acupuncture anesthesia can reduce the accumulation of $\mathrm{Ca}^{2+}$ in brain neurons, prevent $\mathrm{Ca}^{2+}$ overload, mitigate or avoid necrosis of the neurons, and have a protective effect on the ischemic injury of neurons. As a result, the occurrence of cognitive impairment is decreased (20).

In conclusion, compared with simple general anesthesia, combined acupuncture and general anesthesia can stabilize the hemodynamic indexes in elderly patients undergoing subtotal gastrectomy, reduce adverse reactions after operation, and effectively improve immune function. Therefore, this practice should be further popularized.

\section{References}

1. Kelley JR and Duggan JM: Gastric cancer epidemiology and risk factors. J Clin Epidemiol 56: 1-9, 2003.

2. Okano A, Kato S and Ohana M: Helicobacter pylori-negative gastric cancer: advanced-stage undifferentiated adenocarcinoma located in the pyloric gland area. Clin J Gastroenterol 10: 13-17, 2017.

3. Chien TL, Rau KM, Chung WJ, Tai WC, Wang SH, Chiu YC, Wu KL, Chou YP, Wu CC, Chen YH, et al; Gastric Cancer Team: Trousseau's syndrome in a patient with advanced stage gastric cancer. World J Gastroenterol 21: 10049-10053, 2015.

4. Hur H, Lee HY, Lee HJ, Kim MC, Hyung WJ, Park YK, Kim W and Han SU: Efficacy of laparoscopic subtotal gastrectomy with D2 lymphadenectomy for locally advanced gastric cancer: The protocol of the KLASS-02 multicenter randomized controlled clinical trial. BMC Cancer 15: 355, 2015.

5. Fukuchi M, Mochiki E, Ishiguro T, Tsuji Y, Suzuki O, Sobajima J, Baba H, Kumagai Y, Ishibashi K and Ishida H: Evaluation of immunity in elderly patients with unresectable gastric cancer receiving S-1/Lentinan combination chemotherapy. Gan To Kagaku Ryoho 41: 1264-1266, 2014 (In Japanese).

6. Guo Y, Sun L, Zhang J, Li Q, Jiang H and Jiang W: Preventive effects of low-dose dexmedetomidine on postoperative cognitive function and recovery quality in elderly oral cancer patients. Int J Clin Exp Med 8: 16183-16190, 2015. 
7. Larouche E, Tremblay MP, Potvin O, Laforest S, Monetta L, Boucher L, Tremblay P, Belleville S, Lorrain D, Gagnon JF, et al: Normative data for the montreal cognitive assessment in middle-aged and elderly Quebec-French people. Arch Clin Neuropsychol: Sep 13, 2016 (Epub ahead of print).

8. Arevalo-Rodriguez I, Smailagic N, Roqué I, Figuls M, Ciapponi A, Sanchez-Perez E, Giannakou A, Pedraza OL, Bonfil Cosp X and Cullum S: Mini-Mental State Examination (MMSE) for the detection of Alzheimer's disease and other dementias in people with mild cognitive impairment (MCI). Cochrane Database Syst Rev 3: CD010783, 2015.

9. Hu J, La Vecchia C, Negri E, de Groh M, Morrison H and Mery L; Canadian Cancer Registries Epidemiology Research Group: Macronutrient intake and stomach cancer. Cancer Causes Control 26: 839-847, 2015.

10. Ryu MH, Yoo C, Kim JG, Ryoo BY, Park YS, Park SR, Han HS Chung IJ, Song EK, Lee KH, et al: Multicenter phase II study of trastuzumab in combination with capecitabine and oxaliplatin for advanced gastric cancer. Eur J Cancer 51: 482-488, 2015.

11. Fujitani K, Yang HK, Mizusawa J, Kim YW, Terashima M, Han SU, Iwasaki Y, Hyung WJ, Takagane A, Park DJ, et al; REGATTA study investigators: Gastrectomy plus chemotherapy versus chemotherapy alone for advanced gastric cancer with a single non-curable factor (REGATTA): A phase 3, randomised controlled trial. Lancet Oncol 17: 309-318, 2016.

12. Green JS and Tsui BC: Impact of anesthesia for cancer surgery: Continuing professional development. Can J Anaesth 60: $1248-1269,2013$

13. Pearson AM and Lurie JD: Surgical versus nonoperative treatment: How do we choose the right approach to lumbar disk herniation? Pain Manag 4: 247-249, 2014.
14. Erdogan Kayhan G, Gul M, Kayhan B, Gedik E, Ozgul U, Kurtoglu EL, Durmus M and Ersoy MOO: Dexmedetomidine ameliorates TNBS-induced colitis by inducing immunomodulator effect. J Surg Res 183: 733-741, 2013.

15. Hyodo $\mathrm{M}$ and Gega $\mathrm{O}$ : Use of acupuncture anesthesia for normal delivery. Am J Chin Med (Gard City NY) 5: 63-69, 1977.

16. Faircloth AC, Dubovoy A, Biddle C, Dodd-McCue D and Butterworth JF IV: CME Article: Perceptions of acupuncture and acupressure by anesthesia providers: A quantitative descriptive study. Med Acupunct 28: 79-86, 2016.

17. Ballard C, Jones E, Gauge N, Aarsland D, Nilsen OB, Saxby BK, Lowery D, Corbett A, Wesnes K, Katsaiti E, et al: Optimised anaesthesia to reduce post operative cognitive decline (POCD) in older patients undergoing elective surgery, a randomised controlled trial. PLoS One 7: e37410-e37410, 2012.

18. Nascimento CM, Pereira JR, Pires de Andrade L, Garuffi M, Ayan C, Kerr DS, Talib LL, Cominetti MR and Stella F: Physical exercise improves peripheral BDNF levels and cognitive functions in mild cognitive impairment elderly with different bdnf Val66Met genotypes. J Alzheimers Dis 43: 8-91, 2015.

19. Wang J and Wan Y: Acupuncture mechanisms: Anesthesia, analgesia and protection on organ functions. World J Tradit Chin Med 1: 59-66, 2015

20. Gemma M, Nicelli E, Gioia L, Moizo E, Beretta L and Calvi MR: Acupuncture accelerates recovery after general anesthesia: A prospective randomized controlled trial. J Integr Med 13: 99-104, 2015.

This work is licensed under a Creative Commons Attribution-NonCommercial-NoDerivatives 4.0 International (CC BY-NC-ND 4.0) License. 